\title{
Evaluation of the saturation property of vegetation indices derived from sentinel-2 in mixed crop-forest ecosystem
}

\author{
Andualem Aklilu Tesfaye ${ }^{1}$ (D) Berhan Gessesse Awoke $^{1}$
}

Received: 23 July 2019/Revised: 22 May 2020/Accepted: 10 June 2020/Published online: 22 June 2020

(C) The Author(s) 2020

\begin{abstract}
The saturation property of vegetation indices posed a known limitation and this study was motivated to understand the saturation property of three widely used vegetation indices in mixed crop-forest ecosystem where limited knowledge existed. Normalized Difference Vegetation Index (NDVI), Simple Ratio Index (SRI) and Transformed Vegetation Index (TVI) were computed from sentinel-2 bands and; variations among bands and among vegetation indices were evaluated. The study employed green Leaf Area Index (gLAI) Version 1 product, derived from PROBA-V daily data for discriminating the saturation property of the indices. Although the study applied various methods of image preprocessing and processing, best curve fitting and correlation analysis were the key ones. The three vegetation indices: NDVI, SRI, and TVI computed from sentinel-2 bands: four (red) and five (red edge) coupled with bands 8 and 8 a showed some levels of saturation. Nonetheless, TVI computed from bands $8 \mathrm{a}$ and 4 is the best outperforming combination, i.e., the least saturated one and it is an interesting output in a sense that a single index with significantly lower values of noise equivalent green Leaf Area Index as well as having strong association with gLAI is obtained that could be very useful for quantification of gLAI in similar ecosystems. For the rest of the bands and vegetation indices combination of the indices via setting thresholds could be one possible solution.
\end{abstract}

Andualem Aklilu Tesfaye

anduak@yahoo.com

Berhan Gessesse Awoke

Berhanavu@gmail.com

1 Department of Remote Sensing, Ethiopian Space Science and Technology Institute, Addis Ababa University, Addis Ababa, Ethiopia
Keywords Saturation - Vegetation indices - Green Leaf Area Index · Biomass

\section{Introduction}

Remote sensing of vegetation is developed from the very nature of spectral properties of vegetation, i.e. vegetation, overall, exhibit strong absorption in the red band range while higher reflectance in the near-infrared bandwidth. Vegetation indices are used as proxies for understanding temporal and spatial variations of vegetation structure and density.

Though these proxies are used widely, they are associated with different problems and limitations. The saturation nature of vegetation indices is one of the prominent impediments which make them have little use, such as leading to an underestimation of ecosystem productivity in a highly vegetated or densely forested area. For example, NDVI which is the most widely used vegetation index yields poor estimates of vegetation productivity in areas where there is $100 \%$ vegetation cover and during peak of the season it is inadequate for showing important vegetation properties [1-5]. The most logical explanation behind is that the red band $(680 \mathrm{~nm})$ strongly absorbs electromagnetic energy, represented by an exponential function [1] and when canopy cover reaches $100 \%$, the amount of red light that can be absorbed by leaves reaches a peak [1, 5] whereas, Near Infrared Reflectance (NIR) will increase because an addition of leaves results in multiple scattering [6]. In other words, for instance in crop fields, while reflectance in the red region exhibits a nearly flat response once the leaf area index (LAI) exceeds 2, the near-infrared reflectance continues to respond significantly to changes in moderate-to-high vegetation density (LAI 
from 2 to 6). The imbalance between a slight decrease in the red and high NIR reflection results in a slight change in the NDVI ratio, hence, yields a poor relationship with biomass. In order to double the ratio, the NIR reflectance should almost double to compensate for the slight change in red reflectance, however, which is not always the case [6].

As a response, various attempts have been made in addressing this saturation problem that could be put within three groups: mathematical improvement or modification of the indices, comparison, selection and combined use of less sensitive indices and the use of hyperspectral or rededge bands. The Wide Dynamic Range Vegetation Index $\left(\mathrm{WDRVI}=(a * \rho \mathrm{NIR}-\rho \mathrm{red}) /\left(a^{*} \rho \mathrm{NIR}+\rho \mathrm{red}\right)\right)$, which is a result of simple modification of NDVI, proposed, the coefficient $a$ (with values between 0.1 and 0.2 ) and it increases the correlation with vegetation fraction by linearizing the relationship in three crop canopies: wheat, soybean, and maize. The approach resulted in more sensitivity to moderate-to-high LAI (between 2 and 6) which is at least three times greater than that of the NDVI, which enables more robust characterization of crop physiological and phenological characteristics [7].

Vegetation indices were combined taking into account differences in the performance of various vegetation indices to vegetation density and the available bands in sensors. For sensors with spectral bands having red and nearinfrared bands, NDVI combined with Simple Ratio (RVI) resulted in the best combination for maize though such combination is species-specific. Red-edge NDVI and Chlorophyll Red edge (CIred-edge) is recommended for sensors having bands with red-edge and near-infrared regions [8]. Using RapidEye images three improved indices namely $\mathrm{NDVI}_{\text {red\&RE }}$ (red and red-edge NDVI), $\mathrm{MSR}_{\text {red\&RE }}$ (red and red-edge MSR index), and $\mathrm{CI}_{\text {red\&RE }}$ (red and red-edge CI) were developed that combined red and red-edge bands; and these indices compared to existing indices proved to be powerful alternative for LAI estimation of crops with wide chlorophyll range [9].The combined use of NDVI with RVI was also developed after the relationship between NDVI and the ratio vegetation index (RVI) at high NDVI values was assessed. And it produced an empirical equation for estimating saturationadjusted NDVI based on RVI in cornfields that enable better prediction of actual vegetation conditions [10].

Unlike the few numbers of bands in multispectral sensors which are often broad band, hyperspectral sensors offer possibilities of discriminating vegetation indices based on narrow bands in the whole electromagnetic spectrum (350-2500 nm). Many studies acknowledged the importance of narrow-band vegetation indices for estimation of forest canopy LAI [11-15]. Narrow bands placed in the red edge $(680-750 \mathrm{~nm})$ region influenced plant properties, such as canopy biomass and leaf chlorophyll content. The point of maximum slope on the red infrared curve referred to as a red edge position is found to be sensitive to biomass variations for green vegetation in contrast to senescing vegetation and hence less susceptible to saturation problem $[3,16]$. Three methods: NN, PLS and VI were implemented to find informative spectral bands retained for LAI estimation using hyperspectral reflectance. The study took 8 years of observations and results showed that red edge and NIR bands were found to be the most informative [17].

In a study that employs the narrow bands of Hyperion imagery, three major regions have been identified showing the strongest relationship with LAI and namely far-red and red edge (680-740 nm), NIR (885-1134 nm) and SWIR (1639-1790 nm) [18]. Applying a linear model the best narrowband combinations in the boreal forest area revealed an $\mathrm{R}^{2}>0.65$ and much higher $\mathrm{R}^{2}>0.85$ value for $\mathrm{a}$ coniferous forest. Considering the placement of the bands' narrow spectral bands close to the water absorption regions are uniquely useful for estimating LAI. The usefulness of the red edge position (REP) for LAI estimation is associated with the sensitiveness of the REP to leaf and chlorophyll content. That is an increase in the amount of chlorophyll or LAI is related to the longer REP wavelength due to the widening of the chlorophyll absorption region at approximately $680 \mathrm{~nm}[19,20]$. On the other hand, contrasting to SWIR spectral bands, the far-red and red edge is sensitive to species composition, displaying poor relationships over mixed vegetation. Overall, although repeated studies are asserting the importance of red edge and SWIR spectral region, the specific spectral bands providing the strongest relationship with LAI varied across studies [18]. Narrow multispectral bands $(400-800 \mathrm{~nm}$ and $10 \mathrm{~cm}$ resolution) from Unmanned Area Vehicle (UAV) successfully estimated LAI using a modified triangular vegetation index $\left(\mathrm{MTVI}_{2}\right)$ with calibrated and validated $\mathrm{R}^{2}$ of 0.79 and 0.8 respectively in wheat crop [21].

Most of the existing studies on the saturation nature of vegetation indices have focused on crops and understanding in other vegetation types such as forest and grassland owing unique characteristics in terms of productivity are presumably unaddressed [8]. In the meantime, the recently available remote sensing sensor sentinel-2, which is designed and developed with much promise in vegetation studies, came up with three red-edge bands, one red band, two near-infrared bands, and two shortwave infrared bands. In this regard, outputs from very recent studies addressed an estimation of biophysical parameters using simulated and real sentinel-2 data. For instance, simulated sentinel-2 data was applied for estimation of canopy chlorophyll content (CCC), fraction of photosynthetically active radiation absorbed by the vegetation canopy (FAPAR), and 
fraction of photosynthetically active radiation absorbed only by its photosynthesizing components (GFAPAR) in a dynamic subalpine grassland ecosystem [22]. The combination of sentinel-2A with sentinel-1A was applied for high spatial-temporal decametric LAI estimates. For rice fields, LAI estimates were attained by inverting the PROSAIL radiative transfer model with gaussian regression [23]. A very recent study by [24] produced a novel index called SeLI for estimation of gLAI using sentinel-2 bands; and it was implemented using a multi-crop dataset. LAI, by using weighted difference vegetation index could be estimated at a level of $\mathrm{R}^{2}$ of 0.809 using band 4 with $10 \mathrm{~m}$ spatial resolution of sentinel-2 that implying the avoidance of the use of the red-edge bands with $20 \mathrm{~m}$ spatial resolution [25] but the study didn't evaluate the red-edge bands.

Nonetheless, apart from the few studies, in general, understanding the saturation properties of sentinel- 2 bands as the data availability is relatively recent is yet an open area with much-expected progress ahead to fully appreciate the real capability and implement practical methods for estimation of biophysical parameters using real sentinel-2 bands. Therefore, this study is primarily motivated for understanding the sensitivity of the narrow bands of sentinel-2 with respect to saturation in the mixed crop-forest ecosystem. And it is also original in performing the interband variation of the multispectral bands of sentinel-2 in light of explicitly explaining saturation properties. The selection of a mixed ecosystem is purposive as the maximum green leaf area index is obtained often in the highly forested area while crop areas represent low values and hence placing the study in a mixed agricultural-forest ecosystem enables understanding the full saturation characteristics of the bands. Accordingly, this paper evaluates the saturation nature of three widely applied vegetation indices calculated from bands of sentinel-2.

\section{Materials and methods}

\subsection{Study area}

The study site is located in two adjacent crop and forest ecosystems in southeastern Ethiopia. The forest has area coverage of $2671 \mathrm{~km}^{2}$ and an average elevation of 2101masl located within Harenna Forest of the Bale Mountains National Park. The cropland, which is placed in weredas of Arsi-Bale districts, is widely known as part of the highly productive wheat belt of Ethiopia. The cropland covers an area of $590 \mathrm{~km}^{2}$ with an average altitude of 2448 masl (Fig. 1).

\subsection{Data}

This study used the sentinel-2 imagery and Leaf Area Index (LAI) product; hence, to suit intercomparison, equivalent products from the two sensors were collected at similar or close days. Imageries and products were accessed for a specific geographic area and for four time periods (Table 1) so that comparison results will be more reasonable accounting temporal variations.

LAI product used in this study is obtained from the Copernicus Global Land Service (CGLS) Leaf Area Index (LAI) Version 1 product, derived from PROBA-V daily data having $300 \mathrm{~m}$ spatial resolution. It is a 30-days composite, updated every 10 days using a moving window. The PROBA-V LAI Version 1 is derived from the SPOT/ VGT-like Top of Atmosphere (TOA) PROBA-V reflectance in three VNIR spectral bands (B0 (blue), B2 (Red), B3 (NIR)) generated by the PROBA2VGT module. The retrieval methodology is described in [26].

The use of this product is said to have some limitations, notably, the collection $300 \mathrm{~m}$ Version 1 product is not accurate over the wetlands and can provide unrealistic values over water areas. This is explained by the fact that the MODIS products and the CYCLOPES products used to train the neural networks do not perform well over such surfaces. Nonetheless, the accuracy assessments of PROBA-V LAI product at $300 \mathrm{~m}$ spatial resolution over Europe have shown a good overall quality with good spatial and temporal consistency. No major issues were detected, except by the low precision of the NRT guess [27].

\subsection{Image preprocessing and processing}

Six bands of sentinel-2 including Band 4 (central wavelength $(\mathrm{CW})$ of $0.665 \mu \mathrm{m}$, bandwidth (BW) of $30 \mathrm{~nm}$ ), Band $5(\mathrm{CW}=0.705 \mu \mathrm{m}, \mathrm{BW}=15 \mathrm{~nm})$, Band $6(\mathrm{CW}=$ $0.740 \mu \mathrm{m}, \mathrm{BW}=15 \mathrm{~nm})$, Band $7 \quad(\mathrm{CW}=0.783 \mu \mathrm{m}$, $\mathrm{BW}=20 \mathrm{~nm})$, Band $8(\mathrm{CW}=0.842, \mathrm{BW}=115 \mathrm{~nm})$ and Band $8 \mathrm{~A}(\mathrm{CW}=0.865 \mu \mathrm{m}, \mathrm{BW}=20 \mathrm{~nm}$ used for stacking. As the study uses images from different platforms and involves cross-comparison study, for valid geometrical accuracy, image to image registration between inter-sensors was conducted. Then, a subset of images was implemented for all of the three sensors.

Three vegetation indices namely Normalized Difference Vegetation Index (NDVI) or a generic Normalized Difference Index (NDI), Simple Ratio (SRI) and Transformed Vegetation Index (TVI) were derived. Since the original NDVI is specific bandwidth dependent, NDI is more representative nonetheless given the popularity of NDVI it is chosen to use this name. These indices, their respective formulae are presented below, are mainly selected as they 
Fig. 1 Map of the study area
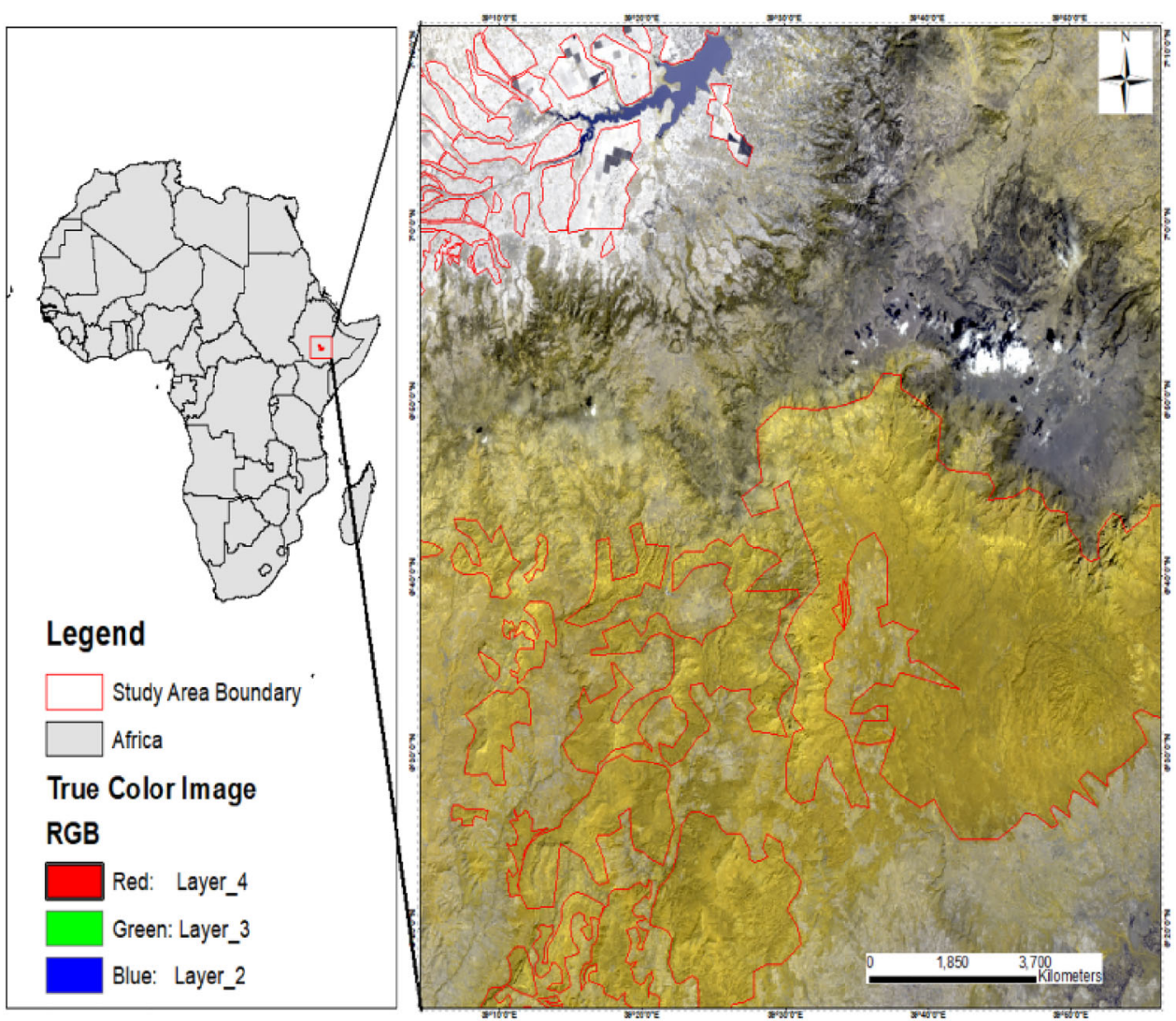

Table 1 Date of Imageries used for the study

\begin{tabular}{llll}
\hline No & Set & Sentinel 2 & LAI 300 \\
\hline 1 & Set One & December 15, 2017 & December 10-20, 2017 \\
2 & Set Two & December 30, 2017 & December 20-31, 2017 \\
3 & Set Three & December 10, 2016 & December 01-10, 2016 \\
4 & Set Four & January 14, 2018 & January 10-20, 2018 \\
\hline
\end{tabular}

employ red, near-infrared bands and used widely for estimating biomass for agricultural and ecological applications [5].

\subsubsection{Normalized difference vegetation index (NDVI)}

The widely used index is probably the Normalized Difference Vegetation Index (NDVI), originally proposed by [28]:

$\mathrm{NDVI}=\frac{N I R 800-R E D 670}{N I R 800+R E D 670}$

Generic Normalized Difference Index (NDI), defined as

$\mathrm{NDI}=\frac{R b-R a}{R b+R a}$
And looking for those wavelengths $\mathrm{a}$ and $\mathrm{b}$ that provides the best correlation with LAI (Leaf Area Index), Ch (chlorophyll) and some other biophysical parameters obtained from experimental data.

\subsubsection{Simple ratio vegetation index (SRI) [29]}

$\mathrm{SRI}=\mathrm{NIR} / \mathrm{RED}$

\subsubsection{Transformed vegetation index (TVI)}

$\mathrm{TVI}=\sqrt[2]{\frac{(N I R-R E D)}{(N I R+R E D)}+0.5}$

\subsection{Saturation property and sensitivity analysis}

Two major analysis methods: correlation and best curve fitting were used to evaluate the saturation nature of the three indices versus gLAI (Table 2). First, a correlation coefficient was computed between the indices and gLAI to discover the presence of any valid association, if the result indicated a strong association, then, the best fit function that describes the relationship will be determined by 
Table 2 Combinations of Sentinel-2 bands used

\begin{tabular}{|c|c|c|}
\hline No. & Red or Red Edge & NIR or Narrow NIR \\
\hline 1 & Band $4-\operatorname{Red}(10 \mathrm{~m})$ & Band 8-NIR(10 m) \\
\hline 2 & Band 5-Vegetation Red Edge $(20 \mathrm{~m})$ & Band $8-\operatorname{NIR}(20 \mathrm{~m})^{\mathrm{a}}$ \\
\hline 3 & Band 6-Vegetation Red Edge (20 m) & Band $8-\operatorname{NIR}(20 \mathrm{~m})^{\mathrm{a}}$ \\
\hline 4 & Band 7-Vegetation Red Edge $(20 \mathrm{~m})$ & Band $8-\mathrm{NIR}(20 \mathrm{~m})^{\mathrm{a}}$ \\
\hline 5 & Band 4-Red(10 m) & Band $8 \mathrm{~A}$-Narrow NIR $(20 \mathrm{~m})^{\mathrm{a}}$ \\
\hline 6 & Band 4-Red(10 m) & Band $8 \mathrm{~A}$-Narrow NIR $(20 \mathrm{~m})^{\mathrm{a}}$ \\
\hline 7 & Band 5-Vegetation Red Edge $(20 \mathrm{~m})$ & Band $8 \mathrm{~A}$-Narrow NIR $(20 \mathrm{~m})^{\mathrm{a}}$ \\
\hline 8 & Band 6-Vegetation Red Edge $(20 \mathrm{~m})$ & Band $8 \mathrm{~A}$-Narrow NIR $(20 \mathrm{~m})^{\mathrm{a}}$ \\
\hline 9 & Band 7-Vegetation Red Edge $(20 \mathrm{~m})$ & Band $8 \mathrm{~A}-$ Narrow NIR $(20 \mathrm{~m})^{\mathrm{a}}$ \\
\hline
\end{tabular}

${ }^{\mathrm{a}}$ Resampled from original $10 \mathrm{~m}$ resolution analyzing the possible mathematical functions using the coefficient of determination and RMSE. Then, a detailed analysis of the saturation properties was implemented via graphical analysis. Furthermore, to understand the saturation properties across the full range region-wise sensitiveness was implemented by computing, the noise equivalent of green leaf area index versus green leaf area index (NE $\Delta$ gLAI vs. gLAI) [30] it tells the accuracy of the gLAI estimation.

$\mathrm{NEgLAI}=\frac{R M S E(V I v s . g L A I)}{d(V I) / d(L A I)}$

Where NE $\Delta \mathrm{gLAI}=$ is the noise equivalent $(\mathrm{NE})$ of $\mathrm{gLAI}$ RMSE (VIvsgLAI) $=$ is the RMSE of the VI versus gLAI relationship $\mathrm{d}(\mathrm{VI} / \mathrm{d}(\mathrm{LAI})=$ is the first derivative of the VI for gLAI.

The NE $\Delta \mathrm{gLAI}$ takes into account not only the RMSE of gLAI estimation but also accounts for the sensitivity of the VI to gLAI, thus providing a metric accounting for both the scattering of the points from the best-fit function and the slope of the best-fit function [8]. The NE $\Delta \mathrm{gLAI}$ provides a measure of how well the VI responds to gLAI across its entire range of variation.

\section{Result and discussion}

\subsection{Correlation matrix of vegetation indices}

Table 3 presented the correlation matrix among NDVI, SRI and TVI values computed via different combinations of sentinel 2 bands as well as with green LAI. Accordingly, for the three of the vegetation index values computed from bands 4 and 5 coupled with bands 8 and 8 a resulted in a strong correlation with green LAI, which is consistent across the four time periods. Additionally, the inter-band association between $\mathrm{b} 4 / \mathrm{b} 5$ with $\mathrm{b} 8 / \mathrm{b} 8 \mathrm{a}$ resulted in a strong correlation. Conversely, NDVI values computed using bands 6 and 7 coupled with bands 8 and 8 a display weak correlation with LAI that is again consistent across the four-time periods, except for b6 with b8a. This result implies that the linear relationship is strong and could be useful for those groups with a strong correlation coefficient, whereas, band $6 / 7$ combined with band $8 / 8$ a linearly is not important.

\subsection{Best fit functions and sensitivity analysis}

Under Sect. 3.1 presented above, important linear associations were revealed and the involved bands were identified and here to understand the saturation nature of these associations, possible fit functions were determined for three fitting curves from three functions: logarithmic, linear and polynomial. The best curve lines for NDVI versus gLAI, where bands $4 / 5$ combined with bands $8 / 8 \mathrm{a}$, are obtained using 3rd order polynomial, and Fig. 2 presented the case for bands 4 with 8 . That is the polynomial function resulted in coefficient of determination of 0.98 compared to 0.96 and 0.95 by logarithmic and linear function respectively.

For inter-band comparisons using the third-order polynomial function, which is selected as the best one, curves of four combinations of NDVI using four bands are calculated and presented in Fig. 3.

As it is well noticed in all the NDVI calculated, the NDVI values computed from b4 and b8 as well as b4 and b8a showed an increasing and higher full range distribution that reaches an approximate value of 0.9 . In contrast, the NDVI values computed from b5 and b8 as well as b5 and b8a have narrow range values that reach a maximum of 0.7 . For all of the four curves, initially, the slope increases sharply followed by decreasing rate of increase and then it became almost to the horizontal level of after $3 \mathrm{gLAI}$.

This observation could be explained using Fig. 4, in which the NE $\Delta$ gLAI increases sharply starting from 3 gLAI that peaks the highest value at around $4.5 \mathrm{gLAI}$ which implies vividly the associated saturation property is emanated from these highest values of NE $\Delta$ gLAI. Besides, 


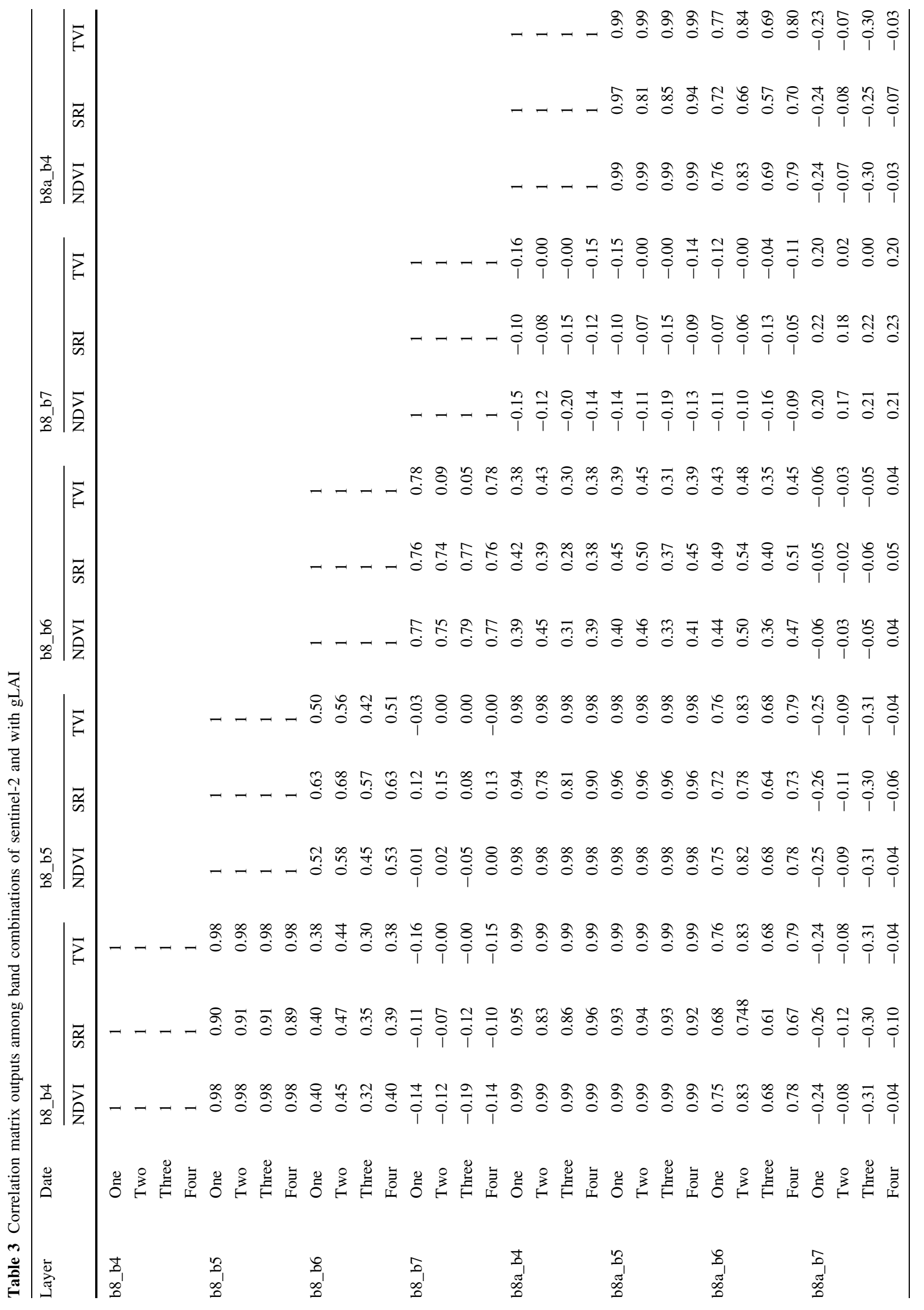




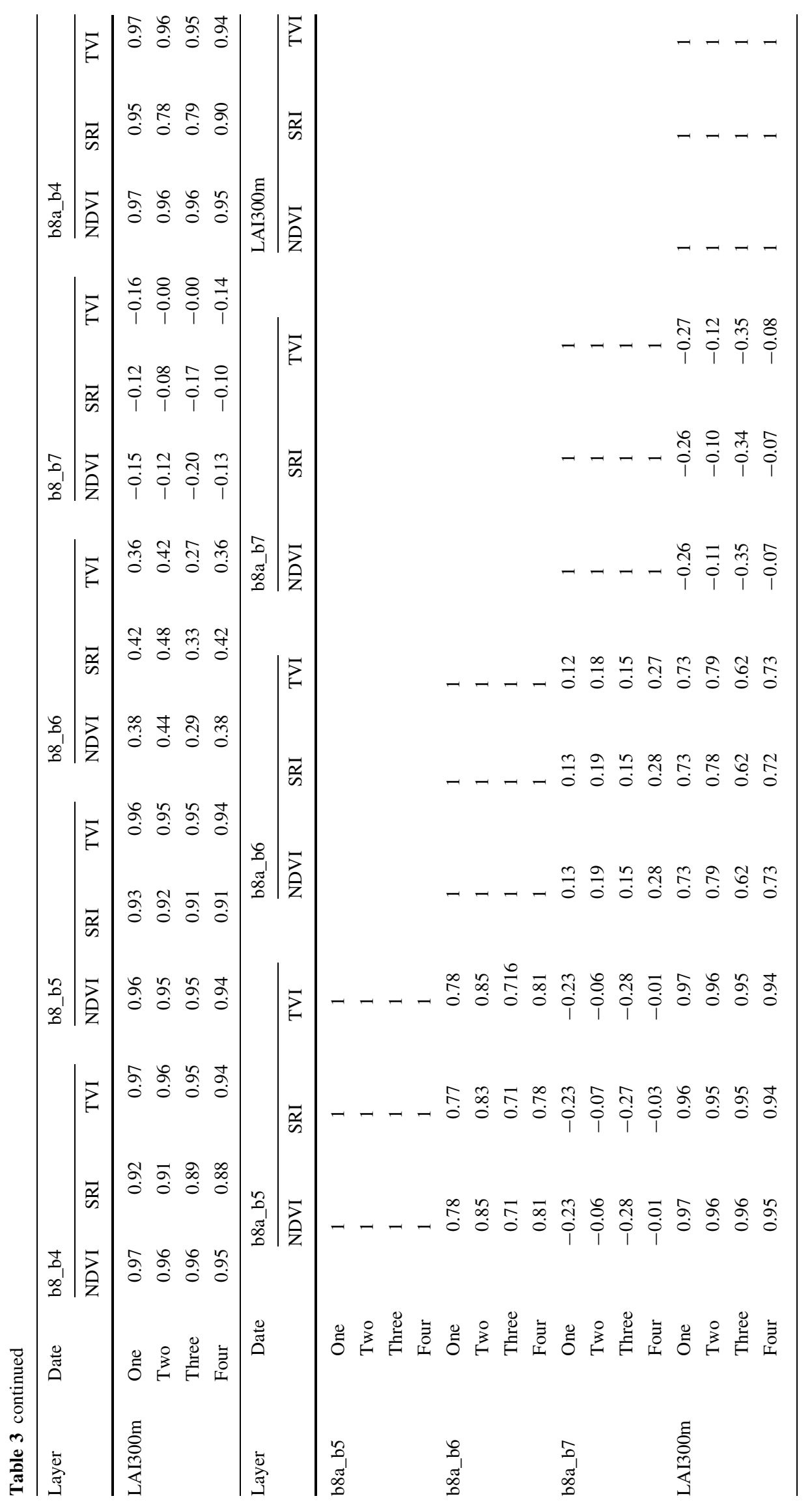




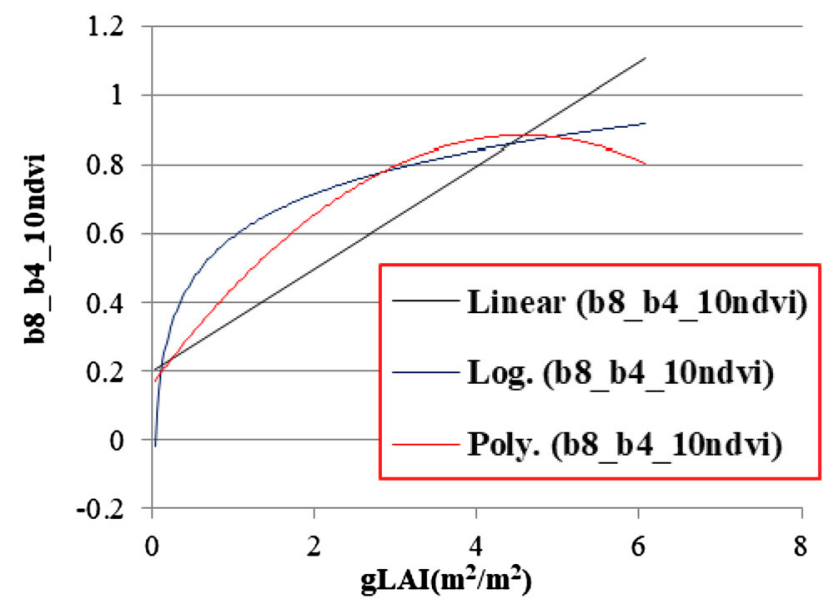

Fig. 2 NDVI (band 4 and 8) plotted versus gLAI for three equations

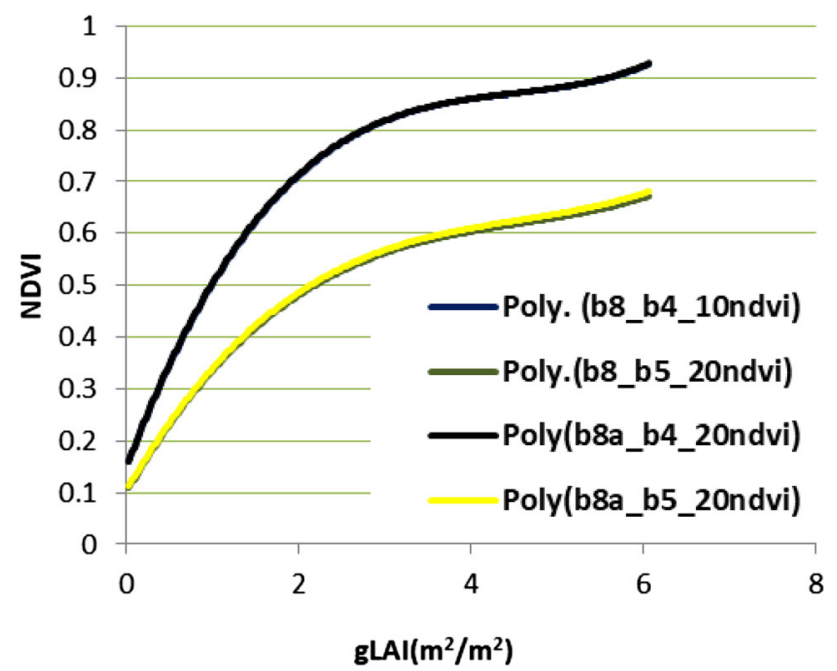

Fig. 3 Best fit function for NDVI (bands 4, 5 with bands 8 and 8a) plotted versus gLAI

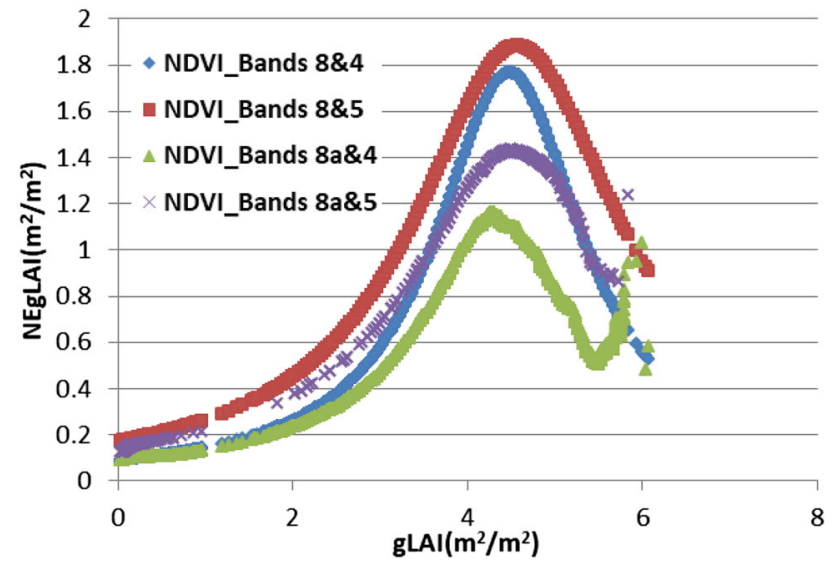

Fig. 4 Noise equivalent of the green leaf area index plotted versus green leaf area index for NDVI for four bands
Fig. 4 indicated among the four curves, NDVI computed using bands $8 \mathrm{a}$ and 4 possesses the lowest value of NE $\Delta$ gLAI. This indicated band 4 combined with band 8 and $8 \mathrm{a}$ is less saturated than band 5 combined with band 8 and $8 \mathrm{a}$, and therefore, it is band four that plays the key role in producing the lowest value of saturation.

Similarly, for SRI, among the tested five fitting functions, exponential growth function resulted in the best-fit function having the highest value of the coefficient of determination of 0.94 . Whereas functions such as power, polynomial, linear and logarithmic revealed coefficient of determination of $0.92,0.85,0.84$ and 0.78 respectively (Fig. 5 showed the case of band 4 coupled with band 8).

To evaluate the interband variation plots were prepared using exponential growth function for bands of 4, 5, 8 and $8 \mathrm{a}$ and displayed in Fig. 6. Among the four plots displayed SRI computed from band 4 coupled with band 8 and $8 \mathrm{a}$ revealed the highest exponential growth functions. In contrast, SRI computed from band 5 coupled with band 8 and $8 \mathrm{a}$ demonstrated relatively low increasing exponential growth function.

The slowly increasing slopes of the SRI curves up to three green leaf area index especially for band combinations of 8 a and 4 as well as 8 and 4 is well supported by highest values NE $\Delta \mathrm{gLAI}$ for these bands as depicted in Fig. 7.

Nonetheless, at higher values of green leaf area index all the bands own smaller values of the NEAgLAI which implies SRI performs well at higher values of green leaf area index compared to NDVI (see Fig. 4 for comparison). Overall, SRI computed using band 4 is less saturated compared to band 5. On the other hand, for TVI, polynomial function evidenced by the highest $\mathrm{R}^{2}$ values of 0.98 and 0.96 produced the best fit plot for the association between TVI and gLAI among the five best possible fitting

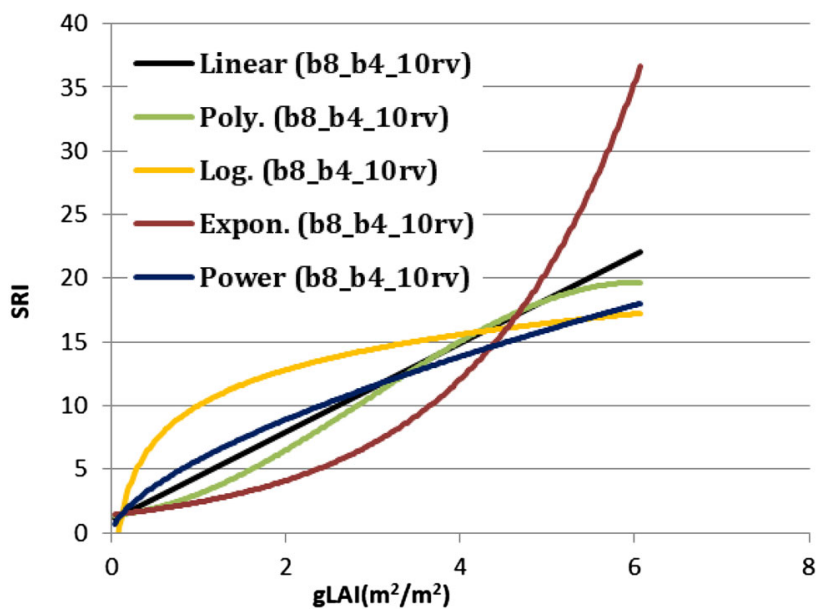

Fig. 5 SRI (band 4 and 8) plotted versus gLAI for five functions 
Fig. 6 Exponential growth function of SRI (bands 4, 5 with bands 8 and $8 \mathrm{a}$ ) plotted versus gLAI

Fig. 7 Noise equivalent of the green leaf area index plotted versus green leaf area index for SRI using four bands
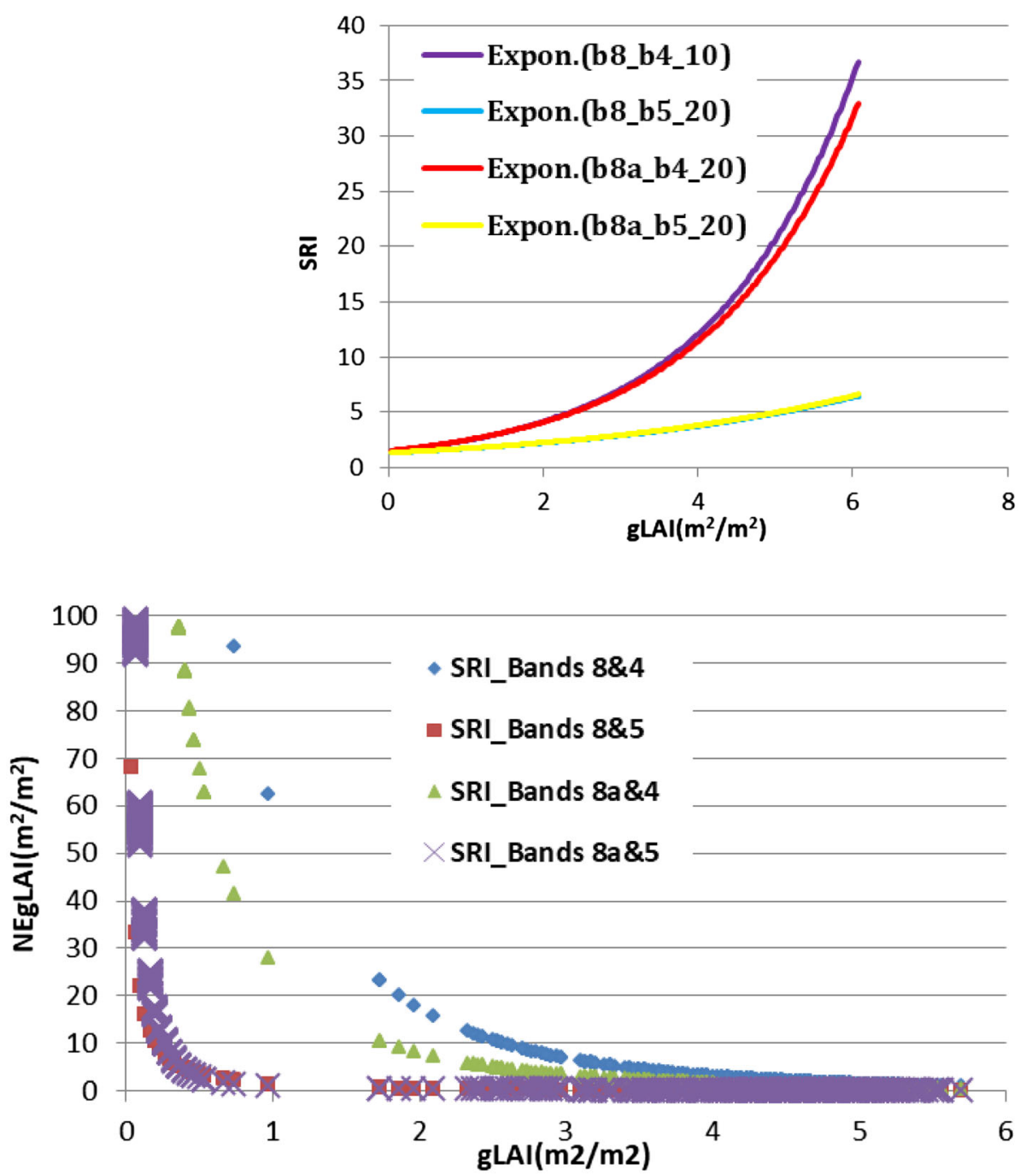

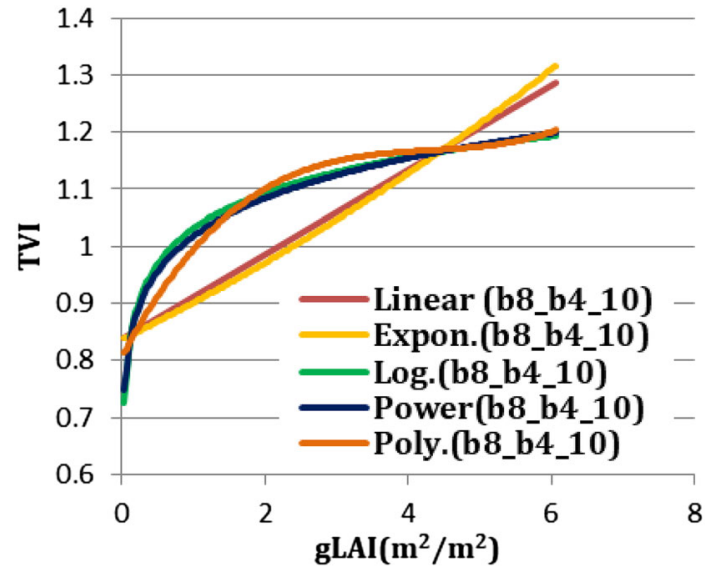

Fig. 8 TVI (band 4 and 8) plotted versus gLAI

functions for bands of 4 and 8(Fig. 8) and for bands of 5 and 8 .

For inter-band comparisons using the polynomial function, which is the best-fit function, plots for TVI versus

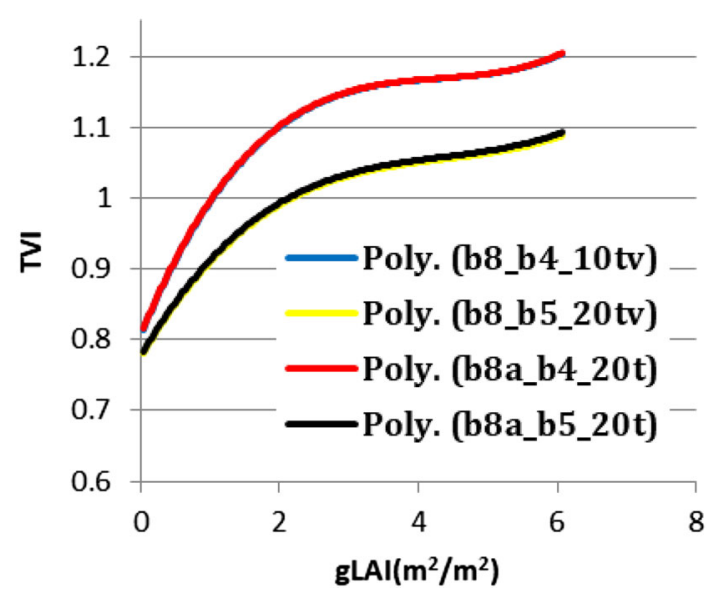

Fig. 9 Best fit function for TVI (bands 4, 5 with bands 8 and 8 a) plotted versus glai

gLAI is presented in Fig. 9. There are two identified groups of curves and these are that of band 4 coupled with bands 8 and $8 \mathrm{a}$ on one hand and band 5 coupled with bands 8 and 
$8 \mathrm{a}$ on the other side. The two groups within the first group have more widely distributed values of TVI that reach up to 1.2 compared to the second group of two curves that are narrowly distributed TVI range of values with a maximum of below 1.1. Thus, the two TVIs in the first group: b8_4 and b8a_b4 are less saturated than b8_b5 and b8a_b5.

As shown in Fig. 10, the NE $\Delta$ gLAI versus gLAI curves for the plots also unveiled similar output, in particular for TVI from bands $8 \mathrm{a}$ and 4 showed not only smaller also consistent values across the full range value of green leaf area index. TVI calculated using bands $8 \mathrm{a}$ and 5 is the second one in terms of having less value of NE $\triangle \mathrm{gLAI}$, as evidenced at 4.5 gLAI the corresponding NE $\Delta$ gLAI is smaller than the values for the rest two bands combinations specifying lower values of NE $\Delta \mathrm{gLAI}$ are associated with band $8 \mathrm{a}$.

Previous researches implemented in agricultural fields using simulated sentinel-2 resulted in comparable findings. That is, using Normalized Difference Index (NDVI), LAI can be derived with $674 \mathrm{~nm}$ and $712 \mathrm{~nm}$ as best performing bands which are positioned closely to sentinel-2 B4 $(665 \mathrm{~nm})$ and the new red edge band, B5(705 nm) [23].Similarly, for potato fields, the use of the $10 \mathrm{~m}$ red band, b4, enabled an estimation of LAI using the weighted difference vegetation index (WDVI) with an $\mathrm{R}^{2}$ of 0.809 and it was stated the avoidance of the red edge bands which are available at $20 \mathrm{~m}$ spatial resolution [25]. In the boreal forest, a study using simulated sentinel-2 bands the highest $\mathrm{R}^{2}$ values resulted from SRI and NDVI (Normalized Vegetation Index) compared to other types of vegetation indices. For effective LAI estimation band 4 combined with band 8 was the best one with $\mathrm{R}^{2}$ of 0.93 [31].

A very recent study by [24] using real sentinel-2 images produced anew green LAI called SeLI which is a normalized index that applied band 5 and band 8a using multicrop data set as the best performing index compared with different tested indices. Using linear fitting an $\mathrm{R}^{2}$ of 0.708 and 0.732 were obtained for the calibrated and validated dataset. Thus, it indicated that despite the difference between the present study area (mixed agricultural-forest) and the indicated output from agricultural areas, results are consistent and agreed.

On the other hand, for the three of the indices that computed from bands of 6 and 7 coupled with bands of 8 and $8 \mathrm{a}$, correlation coefficient values between the three VIs versus gLAI are so small revealing weak association (Table 3). Furthermore, these observations are supported by smaller values of coefficient of determination and among the possible functions, notably linear and non-linear (logarithmic, polynomial, exponential and power), all failed to result in a strong relationship. For instance, both logarithmic and polynomial functions yield coefficient of determination of 0.15 and a very close result of 0.14 is obtained for linear function. Consequently, these bands are not useful for discriminating biomass parameters such as gLAI.

\subsection{Sensitivity analysis of inter-vegetation indices}

In the aforementioned discussions, the saturation characteristics among the bands for the three of the vegetation indices were presented. It is also imperative to understand the variations of the three vegetation indices for estimating of green leaf area index. This is done by analyzing the plot noise equivalent of the green leaf area index versus green leaf area index. Under the previous sections, bands 4 and 5 were obtained as the best performing bands; and in this part, the analysis considered solely these bands.

Accordingly, as shown in Fig. 11a, using bands 8 and 4 for low to medium gLAI values $(<4.2$ gLAI), NDVI has the lowest noise equivalent of green leaf area index value compared to SRI and TVI. On the other hand, for medium to the high value of gLAI, all of the three vegetation indices have closely similar values of NE $\Delta \mathrm{gLAI}$ though TVI has the smallest values.

The analysis for band combinations of 8 and 5 and $8 \mathrm{a}$ and 5 (see Fig. 11 (b and d)) showed very close results. SRI got the largest value of NE $\Delta$ gLAI for gLAI values less than
Fig. 10 Noise equivalent of the green leaf area index plotted versus green leaf area index for TVI using four

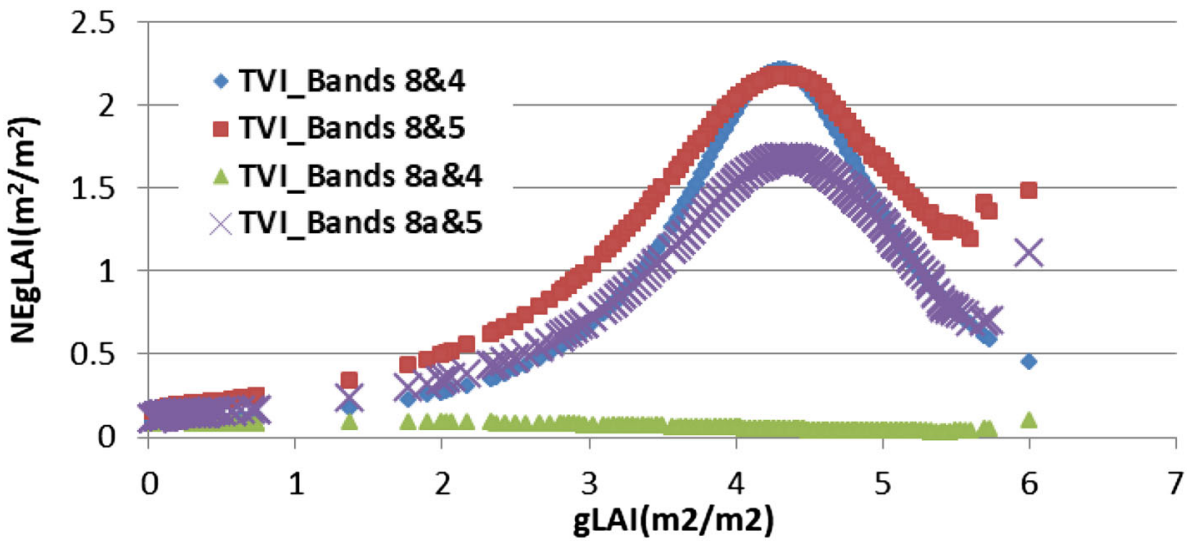


(a)

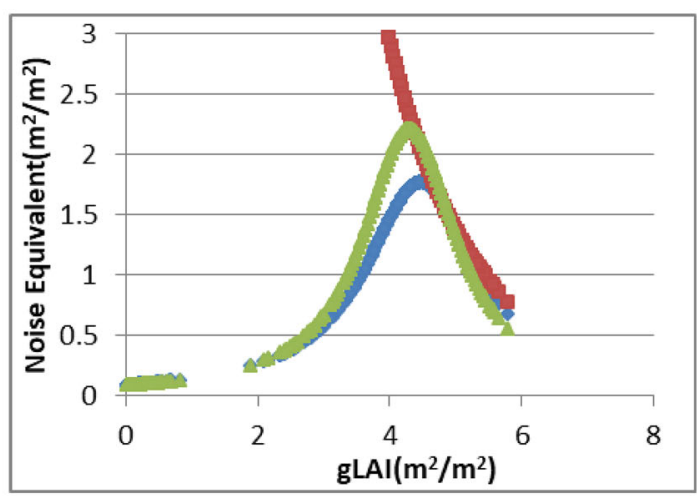

(c)

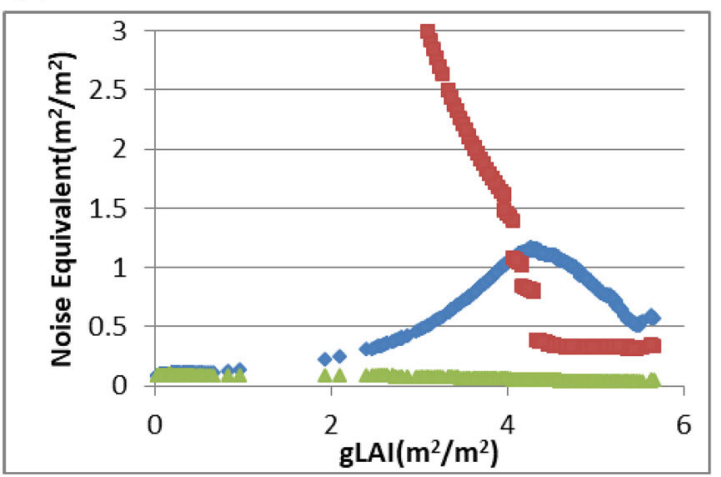

Legend $\bullet$ NDVI (b)

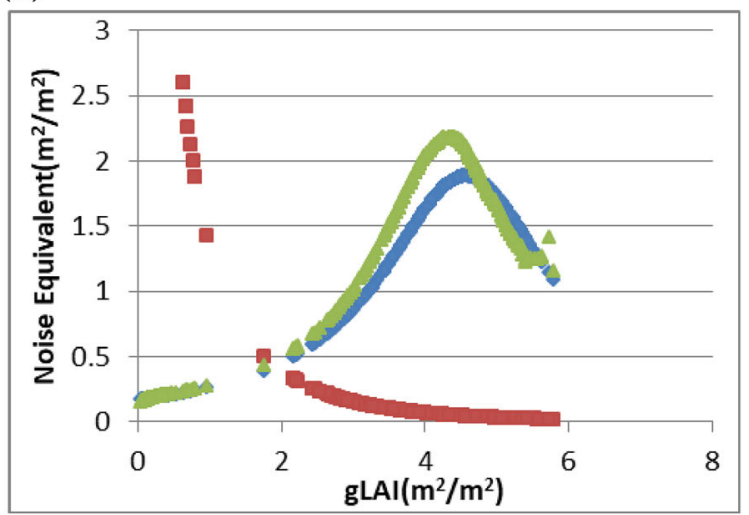

(d)

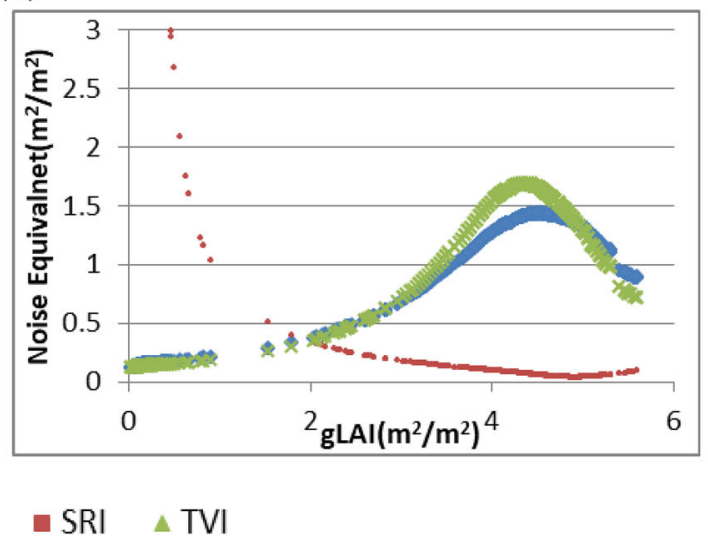

$\begin{array}{llll}\text { (a) Bands } 8 \text { and } 4 & \text { (b) Bands } 8 \text { and } 5 & \text { (c) Bands } 8 \text { a and } 4 & \text { (d) Bands } 8 \text { a and } 5\end{array}$

Fig. 11 Noise equivalent of the green leaf area index plotted versus gLAI for three vegetation indices. a Bands 8 and 4 b Bands 8 and 5 c Bands $8 \mathrm{a}$ and $4 \mathbf{d}$ Bands $8 \mathrm{a}$ and 5

2. At this range, both the NDVI and TVI are characterized by similar small values of NE $\Delta$ gLAI. Beyond 2 gLAI, SRI by far got the lowest values of NE $\triangle \mathrm{gLAI}$ and therefore in the former range either NDVI or TVI is preferred to determine gLAI whereas in the later range SRI outweighs the rest two indices.

On the other hand, among the three of the vegetation indices compared using bands of $8 \mathrm{a}$ and 4(see Fig. 11c) across the full range of gLAI, TVI is characterized by lower values of NE $\Delta \mathrm{gLAI}$ that implies TVI outperforms in terms of its utilization for estimation of gLAI. This is an interesting output in the sense that a single index with significantly lower values of NE $\Delta$ gLAI as well as having a strong association with gLAI is obtained that could be very useful for quantification of gLAI in mixed agricultural and forest ecosystems. For the rest of the bands and vegetation indices combination of the indices setting thresholds could be one possible solution [8].

The outputs from the present study should be considered within the context of the research. As the study employed the VI approach for estimating LAI involving two bands at a time, the application of other methods or approaches that use more number of bands for LAI discrimination, for instance, lookup tables and an approved artificial neural networks could be other capabilities to utilize different bands of sentinel-2 [32].

\section{Conclusion and recommendation}

The three vegetation indices: NDVI, SRI, and TVI computed from sentinel-2 bands: four (red) and five (red edge) coupled with bands 8 and 8 a showed some level of saturation. Across the three of the vegetation indices, the combination of band 4 with $8 \mathrm{a}$ is the least saturated one among all of the evaluated bands. Vegetation indices calculated from band 4 with b8 and b8a are less saturated than vegetation indices computed from band 5 with $\mathrm{b} 8$ and b8a. Nonetheless, TVI computed from bands $8 \mathrm{a}$ and 4 is the best outperforming combination for using as a tool for 
discriminating green leaf area index in a mixed agricultureforest ecosystem. Using linear model interpretation NDVI derived from bands 4 and 5 , though the former showed slightly increased importance, could be reliably used for estimation of a biophysical parameter such as green leaf area index showing $95 \%$ variation. Conversely, other red edge bands such as 6 and 7 combined with bands 8 and $8 \mathrm{a}$ are less significant to apply using the three vegetation indices and then discriminate biomass parameters notably green leaf area index under the current forest ecosystem.

In the present study, though the overall conclusion drew was convincing and well agreed with previous related researches, the green leaf area index was derived from Proba-V sensor and will have some potential limitations that could be associated with error propagation. Therefore, future research might consider the determination of green leaf area index using a more accurate approach that could be set in more controlled experimental plots to come up with better validated and assertive outputs.

\section{Compliance with ethical standards}

Conflict of interest On behalf of all authors, the corresponding author states that there is no conflict of interest.

Open Access This article is licensed under a Creative Commons Attribution 4.0 International License, which permits use, sharing, adaptation, distribution and reproduction in any medium or format, as long as you give appropriate credit to the original author(s) and the source, provide a link to the Creative Commons licence, and indicate if changes were made. The images or other third party material in this article are included in the article's Creative Commons licence, unless indicated otherwise in a credit line to the material. If material is not included in the article's Creative Commons licence and your intended use is not permitted by statutory regulation or exceeds the permitted use, you will need to obtain permission directly from the copyright holder. To view a copy of this licence, visit http://creativecommons. org/licenses/by/4.0/.

\section{References}

1. Tucker, C. J. (1977). Asymptotic nature of grass canopy spectral reflectance. Applied Optics, 16, 1151-1156.

2. Sellers, P. J. (1985). Canopy reflectance, photosynthesis and transpiration. International Journal of Remote Sensing, 6, 1335-1372.

3. Todd, S. W., Hoffer, R. M., \& Milchunas, D. G. (1998). Biomass estimation on grazed and ungrazed rangelands using spectral indices. International Journal of Remote Sensing, 19, 427-438.

4. Gao, X., Huete, A. R., Ni, W., \& Miura, T. (2000). Opticalbiophysical relationships of vegetation spectra without background contamination. Remote Sensing of Environment, 74, 609-620.

5. Thenkabail, P. S., Smith, R. B., \& De Pauw, E. (2000). Hyperspectral vegetation indices and their relationships with agricultural crop characteristics. Remote Sensing of Environment, 71, 158-182.

6. Kumar, L., Schmidt, K., Dury, S., \& Skidmore, A. (2001). Imaging spectrometry and vegetation science. In F. D. van der
Meer \& S. M. de Jong (Eds.), Imaging spectrometry (pp. 111-155). Dordrecht: Kluwer Academic Publishers.

7. Gitelson, A. A. (2004). Wide dynamic range vegetation index for remote quantification of biophysical characteristics of vegetation. Journal of Plant Physiology, 161, 165-173.

8. Nguy-Robertson, A., Gitelson, A. A., Yi, P., Andres, V., Timothy, A., \& Donald, R. (2012). Green leaf area index estimation in maize and soybean: Combining vegetation indices to achieve maximal sensitivity. Agronomy Journal, 104, 1336-1347. https:// doi.org/10.2134/agronj2012.0065.

9. Xie, Q., Dash, J., Huang, W., Peng, D., Qin, Q., Mortimer, H., et al. (2018). Vegetation indices combining the red and red-edge spectral information for Leaf Area Index retrieval. IEEE Journal of Selected Topics in Applied Earth Observations and Remote Sensing, 11, 1482-1493.

10. Gu, Y., Wylie, B. K., Howard, D. M., Phuyal, K. P., \& Ji, L. (2013). NDVI saturation adjustment: A new approach for improving cropland performance estimates in the Greater Platte River Basin, USA. Ecological Indicators, 30, 1-6.

11. Lee, K.-S., Cohen, W. B., Kennedy, R. E., Maiersperger, T. K., \& Gower, S. T. (2004). Hyperspectral versus multispectral data for estimating leaf area index in four different biomes. Remote Sensing of Environment, 91(3-4), 508-520.

12. Schlerf, M., et al. (2005). Remote sensing of forest biophysical variables using HyMap imaging spectrometer data. Remote Sensing of Environment, 95(2), 177-194.

13. Brantley, S. T., Zinnert, J. C., \& Young, D. R. (2011). Application of hyperspectral vegetation indices to detect variations in high leaf area index temperate shrub thicket canopies. Remote Sensing of Environment, 115(2), 514-523.

14. Wu, C., Han, X., Niu, Z., \& Dong, J. (2010). An evaluation of EO-1 hyperspectral Hyperion data for chlorophyll content and leaf area index estimation. International Journal of Remote Sensing, 31(4), 1079-1086.

15. Cui, Z., \& Kerekes, J. P. (2018). Potential of red edge spectral bands in future landsat satellites on agroecosystem canopy green leaf area index retrieval. Remote Sensing, 10, 1458.

16. Mutanga, O., \& Skidmore, A. K. (2004). Narrow band vegetation indices overcome the saturation problem in biomass estimation. International Journal of Remote Sensing, 25(19), 3999-4014. https://doi.org/10.1080/01431160310001654923.

17. Kira, O., Nguy-Robertson, A. L., Arkebauer, T. J., Linker, R., \& Gitelson, A. A. (2016). Informative spectral bands for remote green LAI estimation in $\mathrm{C} 3$ and $\mathrm{C} 4$ crops. Agricultural and Forest Meteorology, 218-219, 243-249.

18. Eigemeier, E., Heiskanen, J., Rautiainen, M., Mõttus, M., Vesanto, V.-H., Majasalmi, T., et al. (2012). Narrowband vegetation indices for estimating boreal forest leaf area index, remote sensing-Applications, Dr. Boris Escalante (Ed.), ISBN: 978-953-51-0651-7, InTech. http://www.intechopen.com/books/ remote-sensing-applications/narrowbandvegetation-indices-forestimatingboreal-forest-leaf-area-index

19. Danson, F. M., \& Plummer, S. E. (1995). Red edge response to forest leaf area index. International Journal of Remote Sensing, 16(1), 183-188.

20. Pu, R., Gong, P., Biging, G. S., \& Larrieu, M. R. (2003). Extraction of red edge optical parameters from hyperion data for estimation of forest leaf area index. IEEE Transaction on Geosciences and Remote Sensing, 41(4), 916-921.

21. Yao, X., Wang, N., Liu, Y., Cheng, T., Tian, Y., Chen, Q., et al. (2017). Estimation of wheat LAI at middle to high levels using unmanned aerial vehicle narrowband multispectral imagery. Remote Sensing, 9, 1304.

22. Sakowska, R., Juszczak, A., \& Gianelle, D. (2016). Remote sensing of grassland biophysical parameters in the context of the 
sentinel-2 satellite mission. Hindawi Publishing Corporation Journal of Sensors Volume 2016, Article ID 4612809.

23. Delegido, J., Verrelst, J., Alonso, L., \& Moreno, J. (2011). Evaluation of sentinel-2 red-edge bands for empirical estimation of green LAI and chlorophyll content. Sensors, 11, 7063-7081. https://doi.org/10.3390/s110707063.

24. Pasqualotto, N., Delegido, J., Wittenberghe, S. V., Rinaldi, M., \& Moreno, J. (2019). Multi-crop green LAI estimation with a new simple sentinel-2 LAI index (SeLI). Sensors, 19, 904. https://doi. org/10.3390/s19040904.

25. Clevers, J. G. P. W., Kooistra, L., \& van den Brande, M. M. M. (2017). Using Sentinel-2 data for retrieving LAI and leaf and canopy chlorophyll content of a potato crop. Remote Sensing, 9, 405.

26. Baret, F., Hagolle, O., Geiger, B., Bicheron, P., Miras, B., Huc, M., et al. (2007). LAI, fAPAR and fCover CYCLOPES global products derived from VEGETATION. Part 1: Principles of the algorithm. Remote Sensing of Environment, 110, 275-286.

27. Smets, B., Jacobs, T., \& Verger, A. (2017). Leaf Area Index (LAI) fraction of Photosynthetically Active Radiation (FAPAR) Fraction of Vegetation Cover (FCOVER) Collection $300 \mathrm{M}$. Version 1. Issue I1.50. Gio Global Land Component-Lot I"
Operation of the Global Land Component" Framework Service Contract No 388533 (JRC) and Imagine. Product user manual.

28. Rouse, J. W., Haas, R. H., Schell, J. A., \& Deering, D. W. (1973). Monitoring vegetation systems in the great plains with ERTS. In Third ERTS symposium, Washington, DC (NASA), (pp. 309-317).

29. Jordan, C. F. (1969). Derivation of leaf area index from quality of light on the forest floor. Ecology, 50, 663-666.

30. Viña, A., \& Gitelson, A. A. (2005). New developments in the remote estimation of the fraction of absorbed photosynthetically active radiation in crops. Geophyiscal Research Letters. https:// doi.org/10.1029/2005GL023647.

31. Majasalmi, T., \& Rautiainen, M. (2016). The potential of Sentinel-2 data for estimating biophysical variables in a boreal forest: A simulation study. Remote Sensing Letters, 7(5), 427-436.

32. Richter, K., Hank, T. B., Vuolo, F., Mauser, W., \& D’Urso, G. (2012). Optimal exploitation of the sentinel-2 spectral capabilities for crop leaf area index mapping. Remote Sensing, 4, 561-582. https://doi.org/10.3390/rs4030561.

Publisher's Note Springer Nature remains neutral with regard to jurisdictional claims in published maps and institutional affiliations. 